\title{
ANÁLISE MICROBIOLÓGICA DE ÁGUA FILTRADA POR FILTROS DOMÉSTICOS EM AMBIENTE HOSPITALAR
}

\author{
EMERSON DANGUY CAVASSIN ${ }^{1}$ \\ RENATA APARECIDA BELEI ${ }^{2}$ \\ LUIZA RITA PACHENSKI ${ }^{3}$ \\ CAMILA HELEN OLIVEIRA \\ CLAUDIA M. DANTAS CARRILHO+ \\ MARCIA R. ECHES PERUGINI ${ }^{5}$
}

\begin{abstract}
CAVASSIN, E. D.; BELEI, R. A.; PACHENSKI, L. R.; OLIVEIRA, C. H.; CARRILHO, C. M. D.; PERUGINI, M. R. E. Análise microbiológica de água filtrada por filtros domésticos em ambiente hospitalar. Semina: Ci. Biol. Saúde, Londrina, v. 20/21, n. 2, p. 49-56, jun. 1999/2000.
\end{abstract}

\begin{abstract}
RESUMO: A água potável tem sido descrita como reservatório de vários microrganismos. No mercado existe grande variedade de filtros domésticos, os fabricantes garantem a pureza da água processada por seus equipamentos algumas vezes de maneira equivocada. Em um ambiente hospitalar o controle da água é crucial como forma de reduzir a incidência de infecções. Com o objetivo de verificar o papel dos filtros domésticos como fonte de contaminação da água em ambiente hospitalar, foi realizado um estudo em amostras de água obtida por filtração, antes e após retrolavagem, de 26 filtros instalados em diferentes pontos do hospital, totalizando 78 culturas. Como controle foram analisadas, também, amostras de água não filtrada da rede de água do hospital, coletadas de torneiras próximas ao filtro analisado. As amostras foram avaliadas microbiologicamente através de culturas quantitativas para bactérias mesófilas e coliformes. Realizado também monitoramento dos teores de cloro. Não foi verificado qualquer contaminação nas amostras da rede e o teor de cloro se manteve em 1,5 ppm. Com relação às amostras filtradas antes $e$ após retrolavagem não houve desenvolvimento de coliformes, entretanto, constatou-se a presença de bactérias mesófilas em 19,3\% ( $p=0,056)$ em contagens que variaram de 30 a $100 \mathrm{UFC} / \mathrm{ml}$, com teor de cloro variando de 0,0 a 1,5 ppm. Verificamos que a filtração por este método não assegura a total qualidade da água produzida, podendo ainda vir a ser uma fonte de contaminação.
\end{abstract}

PALAVRAS-CHAVE: Microbiologia; água; coliformes; filtros de água; bactérias mesófilas.

\section{INTRODUÇÃO}

Quando os cuidados de tratamento, purificação ou filtração da água não são realizados há um aumento do risco de infecções decorrentes de seu uso (Rutala \& Weber, 1991). A água potável tem sido descrita como um reservatório de vários microrganismos como bactérias, vírus e protozoários, e sua contaminação uma importante causa de surtos de diarréia, tanto em países desenvolvidos quanto em desenvolvimento, apresentando uma prevalência de $2,1 \%$ e 6,1\%, respectivamente (Roberts \& Soave, 1997).

No mercado brasileiro existe grande variação entre os tipos de filtros domésticos, com diferentes tecnologias e preços. No momento da escolha do modelo a ser utilizado, o consumidor espera eliminar contaminantes microbianos e químicos. Com esta finalidade, um dos modelos mais vendidos no Brasil realiza a filtragem da água através de 04 componentes: a dolomita e o quartzo, que filtram as impurezas sólidas; o carvão ativado, que retém os componentes químicos da água, como o cloro e o cobre, mas que não garante a retenção de microrganismos e o carvão ativado impregnado com prata coloidal, que atua visando inibir um possivel crescimento bacteriano e formação de biofilme, através da liberação de ions Ag(Daschner, 1996). Este filtro possui também um processo de retrolavagem que deveria permitir a limpeza interna do sistema. Assim, os fabricantes confiam na pureza da água processada por seus equipamentos.

\footnotetext{
Bioquímico Microbiologista do SCIH - HURNP

2 Enfermeira do SCIH - HURNP, Docente de Enfermagem UNOPAR

3 Acadêmica de Enfermagem

${ }^{4}$ Médica Infectologista do SCIH - HURNP, Docente

5 Microbiologista do SCIH - HURNP, Docente de Microbiologia Clínica
} 
Grande parte dos consumidores não valoriza os cuidados de manutenção, indispensáveis após a aquisição destes produtos, além de não possuir mecanismos para detectar falhas no processo de filtração. Deste modo, estas unidades domésticas de filtração não são regulamentadas nos termos da qualidade microbiológica da água produzida (Daschner, 1996; Payment, 1989), deixando o consumidor sem meios de avaliar a relação custo/ beneficio na sua aquisição e uso.

Sabe-se que muitos microrganismos não coliformes como bacilos Gram-negativo não fermentadores e mesmo enterobactérias além de micobactérias saprófitas podem ter crescimento sustentado mesmo em águas relativamente puras. Além disto outras bactérias como Yersinia enterocolitica, Vibrio cholerae, Escherichia coli enterotoxigênica, Salmonella spp., Shigella sonnei e Campylobacter jejuni podem contaminar a água potável e causar infecções. Podem ser observados ainda, em reservatórios de água, representantes dos protozoários como Cryptosporidium parvum, Giardia lamblia e Entamoeba histolyitica, e vírus, como o da Hepatite A (Smith \& Rose, 1990; Le Chevallier et al, 1991; Rutala \& Weber, 1991; CDC, 1994).Embora a maioria dos contaminantes da água não sejam considerados patogênicos, alguns destes podem atuar como patógenos oportunistas (Mendes, 1998).

A legislação brasileira estabelece na Portaria $n^{\circ}$ 36, do Ministério da Saúde, de 30 de janeiro de 1990, critérios físico-químicos e microbiológicos para a qualidade da água potável. Fica determinado que a presença de coliformes deve ser inferior a 1 (uma) Unidade Formadora de Colônia (UFC) por $100 \mathrm{ml}$ de água (Brasil, 1990). Sendo assim, um marcador de poluição fecal. Porém, nem sempre sua ausência exclui a possibilidade desta água estar contaminada por agentes de interesse clínico, como por exemplo protozoários (Payment et al., 1991; Rutala \& Weber, 1991). A densidade elevada de microrganismos na água pode determinar a deterioração de sua qualidade, com desenvolvimento de odores esabores desagradáveis, podendo também apresentar riscos à saúde dos consumidores. A Agência de Proteção Ambiental Americana (EPA) sugere contagens não superiores a $500 \mathrm{UFC/} \mathrm{ml}$ de bactérias mesófilas em água potável, o mesmo sendo aceito no Brasil (Brasil, 1990). Enquanto que, na Alemanha, este limite é de 100 UFC/ml (Daschner, 1996).

As estações municipais de tratamento de água são as responsáveis pela manutenção da qualidade fisico-química e microbiológica da água tratada (Pires, 1990). De acordo com a Companhia de Saneamento do Paraná (SANEPAR), responsável pelo tratamento e abastecimento de água no município de Londrina, são realizados testes freqüentes de controle da qualidade, avaliando os seguintes parâmetros: a) bacteriológico: para verificar a presença de coliformes totais, fecais e do vibrião da cólera; b) cromatográfico: para determinar a presença de pesticidas; c) físico-químico: para análise de 27 parâmetros de importância sanitária.

Em sistemas públicos de descontaminação e tratamento de água utiliza-se o cloro, elemento de reconhecido poder desinfetante, tanto na sua forma elementar como na forma de compostos (Brasil,1988). A World Health Organization (WHO, 1984) e a Portaria $n^{\circ} 36$ (Brasil, 1990) recomendam um teor mínimo de 0,5 partes por milhão ( $\mathrm{ppm}$ ) de cloro ativo no tratamento da água para assegurar sua qualidade microbiológica, porém, existem microrganismos que toleram tal concentração. Smith \& Rose (1990) e Center for Disease Control and Prevention (CDC, 1994), relatam casos de surtos por Cryptosporidium parvum mesmo em águas com teores aceitáveis de cloro.

O cloro mantém a qualidade microbiológica da água tratada durante o tempo em que é transportada e armazenada. Na cloração da água, parte do cloro aplicado é consumido em reação com as impurezas presentes, permanecendo o restante disponivel. Neste contato com a água formam-se vários produtos, sendo o ácido hipocloroso o responsável pela atividade antimicrobiana que, quando na concentração de 0,5 a 6 ppm, é suficiente para eliminar bactérias, vírus e a maioria dos protozoários, com exceção do Criptosporydium parvum, que suporta concentrações de até 16.000 ppm (Smith \& Rose, 1990; CDC, 1994). Alguns fungos e esporos bacterianos também exigem uma concentração maior de cloro.

\section{OBJETIVOS}

Considerando a importância da água na propagação de microrganismos que apresentam riscos de infecção, especialmente em pacientes imunodeprimidos, a Comissão de Controle de Infecção Hospitalar do HURNP propôs um estudo com o objetivo de verificar o papel dos filtros domésticos como fonte de contaminação da água em ambiente hospitalar e verificar a eficácia da retrolavagem na redução de contaminação, bem como monitorar os teores de cloro da água proveniente da rede de abastecimento e da água filtrada como forma de minimizar a contaminação desta água.

Em um ambiente hospitalar, entender os mecanismos de aquisição e os possiveis reservatórios de agentes nosocomiais, dentre eles a água do 
hospital, é crucial para desenvolver métodos que reduzam a prevalência das infecções hospitalares (Rutala \& Weber, 1991).

\section{MATERIAIS E MÉTODOS}

Ao tentar garantir a qualidade da água consumida pela população do hospital, em 1995 o Hospital Universitário Regional do Norte do Paraná adquiriu e instalou em todas as suas unidades cerca de 60 filtros de sistema fechado de uso doméstico, com capacidade de fornecer água em temperatura natural e refrigerada, que realiza o processo de filtração através da dolomita, quartzo, carvão ativado e prata coloidal.

O estudo foi realizado em um período de três meses, sendo selecionados 26 filtros para análise tendo como critérios de seleção a freqüência de uso (classificados como de pouco, médio ou muito uso), a localização (aqueles com uma torneira comum próxima, para possibilitar a coleta da amostra controle), a população servida (preferencialmente os utilizados por pacientes, funcionários, alunos, residentes) e a idade do filtro (aqueles com maior tempo de uso).

Após periodo de definição do protocolo de pesquisa e treinamento da equipe foram iniciadas as coletas, análises microbiológicas e a determinação do teor de cloro das amostras obtidas. Foram coletadas 3 amostras de cada filtro, uma filtrada antes e outra após retrolavagem e uma terceira amostra não filtrada, da rede de água hospitalar. Para obtenção da água filtrada antes e após retrolavagem foram desprezados os primeiros 600 $\mathrm{ml}$ de água filtrada e coletados em frasco estéril os $110 \mathrm{ml}$ seguintes. A retrolavagem foi realizada através de procedimento padrão de acordo com as orientações fornecidas pelo fabricante: após o escoamento de água por 5 minutos, pelo sistema de retrolavagem, desprezou-se a água filtrada por mais 5 minutos antes da coleta de pós-retrolavagem. Da torneira mais próxima do filtro analisado desprezou-se a água por cerca de 1 minuto e coletou-se $110 \mathrm{ml}$ em frasco estéril.

Todas as amostras tiveram também seu teor de cloro dosado por técnica de titulação colorimétrica visual (Genkit, Genco, São Paulo).
A avaliação microbiológica das amostras foi realizada com culturas quantitativas para bactérias mesófilas e quali/quantitativas para coliformes fecais e totais. As bactérias mesófilas foram quantificadas em duplicata pela técnica da semeadura em profundidade com agar Plated Count Agar (PCA), partindo-se da amostra pura e passando-se por diluições seriadas de 1:10 e 1:100. Após incubação a $35^{\circ} \pm 0,5^{\circ} \mathrm{C}$ por 72 horas, em atmosfera ambiente, feita a contagem macroscópica das unidades formadoras de colônias (UFC) com auxílio do contador Phoenix CP 608. Foram consideradas significativas as placas que apresentaram crescimento entre 30 e 300 UFC (Brasil, 1990). Os coliformes totais e fecais foram identificados e quantificados através de método colorimétrico com o kit comercial Colilert Test KitTM (Quanti Tray 51, IDEXX, Westbrook, USA) que se baseia na utilização diferenciada do substrato MUG 4 metil umbeliferil beta $\mathrm{D}$-galactosidade e 4 metil umbeliferil beta $\mathrm{D}$ glucuronideo (Cenci, 1993).

\section{RESULTADOS}

Não foi verificada qualquer contaminação nas amostras de água não filtrada tanto com relação a bactérias mesófilas quanto a coliformes (Tabelas 1 e 2) e o teor de cloro se manteve o mesmo (1,5 ppm) em todas as amostras analisadas (Tabela 3).

Com relação as amostras filtradas antes e após retrolavagem não foi constatado desenvolvimento de coliformes totais e/ou fecais em nenhuma delas (Tabela 1). Entretanto, verificou-se a presença de bactérias mesófilas em $05(19,3 \% / p=0,053)$ dos filtros analisados em contagens que variaram de 30 a100 UFC/ml (Tabela 2). O teor de cloro tanto entre amostras contaminadas quanto não contaminadas variou de 0,0 a 0,5 ppm para a maioria das amostras, enquanto duas das amostras filtradas mantiveram o teor original de $1,5 \mathrm{ppm}$.

Comparando-se a quantidade de colônias isoladas da água antes e após retrolavagem verificouse que em 03 delas (setor de pediatria, tisiologia e hemodiálise) houve diminuição do número de microrganismos recuperados após retrolavagem, entretanto em duas delas (filtro da cozinha e lactário) houve um aumento de 30 para $100 \mathrm{UFC} / \mathrm{ml}$ após retrolavagem (Tabela 2). 
Tabela 1 - Distribuição das amostras segundo análise quantitativa de coliformes fecais e totais da água filtrada pré e pós retrolavagem e água da rede não filtrada.

\begin{tabular}{|c|c|c|c|}
\hline$\overline{\text { SETOR }}$ & $\begin{array}{l}\text { Agua filtrada } \overline{P R E} \\
\text { retrolavagem }\end{array}$ & $\begin{array}{l}\text { Agua filtrada } \mathrm{POS} \\
\text { retrolavagem }\end{array}$ & $\begin{array}{l}\text { Água da rede } \\
\text { Não filtrada }\end{array}$ \\
\hline CENTRO MATERIAIS & Negativa & Negativa & Negativa \\
\hline CENTRO CIRÚRGICO & Negativa & Negativa & Negativa \\
\hline ENFERMARIA MASCULINA & Negativa & Negativa & Negativa \\
\hline ENFERMARIA FEMININA & Negativa & Negativa & Negativa \\
\hline TISIOLOGIA - P. ENFERM. & Negativa & Negativa & Negativa \\
\hline TISIOLOGIA - CORREDOR & Negativa & Negativa & Negativa \\
\hline MOLÉSTIAS INFECCIOSAS & Negativa & Negativa & Negativa \\
\hline MATERNIDADE & Negativa & Negativa & Negativa \\
\hline PEDIATRIA & Negativa & Negativa & Negativa \\
\hline UTI - PEDIÁTRICA & Negativa & Negativa & Negativa \\
\hline UTI - NEONATAL & Negativa & Negativa & Negativa \\
\hline UTI - I & Negativa & Negativa & Negativa \\
\hline UTI - II & Negativa & Negativa & Negativa \\
\hline ENDOSCOPIA & Negativa & Negativa & Negativa \\
\hline HEMODIÁLISE & Negativa & Negativa & Negativa \\
\hline HEMOCENTRO & Negativa & Negativa & Negativa \\
\hline LABORATÓRIO CLÍNICO & Negativa & Negativa & Negativa \\
\hline LABORATÓRIO URGÊNCIA & Negativa & Negativa & Negativa \\
\hline PRONTO SOCORRO & Negativa & Negativa & Negativa \\
\hline PRONTO SOCORRO PED. & Negativa & Negativa & Negativa \\
\hline COPA 1 & Negativa & Negativa & Negativa \\
\hline COPA 2 & Negativa & Negativa & Negativa \\
\hline BANCO DE LEITE & Negativa & * & Negativa \\
\hline LACTÁRIO & Negativa & Negativa & Negativa \\
\hline COZINHA & Negativa & Negativa & Negativa \\
\hline
\end{tabular}

Tabela 2 - Dstribuição das amostras segundo análise quantitativa de bactérias mesófilas da água filtrada pré e pós retrolavagem e água da rede não filtrada

\begin{tabular}{|c|c|c|c|}
\hline SETOR & $\begin{array}{l}\text { Agua filtrada PRE } \\
\text { retrolavagem }\end{array}$ & $\begin{array}{l}\text { Agua filtrada POS } \\
\text { retrolavagem }\end{array}$ & $\begin{array}{l}\text { Agua da rede } \\
\text { Não filtrada }\end{array}$ \\
\hline CENTRO MATERIAIS & Negativa & Negativa & Negativa \\
\hline CENTRO CIRÚRGICO & Negativa & Negativa & Negativa \\
\hline ENFERMARIA MASCULINA & Negativa & Negativa & Negativa \\
\hline ENFERMARIA FEMININA & Negativa & Negativa & Negativa \\
\hline TISIOLOGIA - P. ENFERM. & $90 \cup F C / m l$ & $30 \mathrm{UFC} / \mathrm{ml}$ & Negativa \\
\hline TISIOLOGIA - CORREDOR & Negativa & Negativa & Negativa \\
\hline MOLÉSTIAS INFECCIOSAS & Negativa & Negativa & Negativa \\
\hline MATERNIDADE & Negativa & Negativa & Negativa \\
\hline PEDIATRIA & $100 \mathrm{UFC} / \mathrm{ml}$ & $30 \mathrm{UFC} / \mathrm{ml}$ & Negativa \\
\hline UTI - PEDIÁTRICA & Negativa & Negativa & Negativa \\
\hline UTI - NEONATAL & Negativa & Negativa & Negativa \\
\hline UTI - I & Negativa & Negativa & Negativa \\
\hline UTI - II & Negativa & Negativa & Negativa \\
\hline ENDOSCOPIA & Negativa & Negativa & Negativa \\
\hline HEMODIÁLISE & $40 \mathrm{UFC} / \mathrm{ml}$ & 30 UFC/ml & Negativa \\
\hline HEMOCENTRO & Negativa & Negativa & Negativa \\
\hline LABORATÓRIO CLÍNICO & Negativa & Negativa & Negativa \\
\hline LABORATÓRIO URGÊNCIA & Negativa & Negativa & Negativa \\
\hline PRONTO SOCORRO & Negativa & Negativa & Negativa \\
\hline PRONTO SOCORRO PED. & Negativa & Negativa & Negativa \\
\hline COPA 1 & Negativa & Negativa & Negativa \\
\hline COPA 2 & Negativa & Negativa & Negativa \\
\hline BANCO DE LEITE & Negativa & * & Negativa \\
\hline LACTÁRIO & 30 UFC/ml & $100 \mathrm{UFC} / \mathrm{ml}$ & Negativa \\
\hline COZINHA & $30 \mathrm{UFC} / \mathrm{ml}$ & $100 \mathrm{UFC} / \mathrm{ml}$ & Negativa \\
\hline
\end{tabular}


água pura após o teste. Pela dificuldade de limpeza mecânica interna, o biofilme formado durante a filtração mantêm-se presente, contaminando a partir de então toda a água pura filtrada por ele. Em experimento semelhante, com duração de 3 anos, Geldreich (1985) contaminou amostras com cepas de patógenos oportunistas normalmente encontrados em água como Pseudomonas aeruginosa e Serratia marcescens, também coliformes fecais e totais e Salmonella typhimurium

. Todas em contagens iniciais conhecidas de 200 a $300 \mathrm{UFC} / \mathrm{ml}$. Avaliando a recuperação destes mesmos microrganismos na água filtrada após o teste, encontrou Pseudomonas até 120 dias e em contagens de até $850 \mathrm{UFC} / \mathrm{ml}$, Serratia e os coliformes totais de 5 a 156 dias, enquanto que Salmonela e E. coli não foram mais recuperadas após o teste, indicando não terem "colonizado" os filtros testados.

Daschner (1996), trabalhando com águas de uma rede que apresentavam contagens de mesófilas entre 2 a $300 \mathrm{UFC} / \mathrm{ml}$, demonstrou aumento nestes valores após a filtração em $64 \%$ das amostras analisadas $(n=34)$. Quando trabalhando sob temperatura ambiente $\left(22^{\circ} \mathrm{C}\right)$ esse aumento era flagrante após quatro dias de uso. Por outro lado, sob refrigeração $\left(4^{\circ} \mathrm{C}\right)$, o mesmo acontecia somente após o décimo quarto dia, evidenciando a influencia da temperatura no tempo de formação de biofilme e "regrow".

Sabe-se que materiais plásticos poliméricos são capazes de sustentar a formação de biofilme quando em contato com água (Daschner, 1996). Quanto a prata, há indícios de que os ions $\mathrm{Ag}^{-}$após serem liberados necessitem de algum tempo para exercer seu papel antibacteriano, tendo ai um fator limitante de sua ação (Daschner, 1996).

Desse modo, a água contaminada ao passar pelo filtro, pode levar à sua colonização, passando então a eliminar esse microrganismo em toda a água filtrada, por períodos e em contagens que podem variar de acordo com o gênero do microrganismo, o tempo em que o filtro ficou em desuso e a temperatura ambiente (Geldreich, 1985). Com base na tabela 2, não houve crescimento em nenhuma amostra da água da rede não filtrada. Porém, tal resultado não exclui a possibilidade de que os filtros tenham, emalgummomento, recebido contaminantes, dando início a sua colonização.

Os teores de cloro encontrados neste estudo ficaram dentro do limite de referência para água potável, 1,5 ppm de cloro ativo (tabela 3) (Brasil, 1990). Após a filtração, estes valores caíram para uma faixa de 0,0 a 0,5 ppm, o que se justifica pela atuação do carvão ativado adsorvendo este elemento durante o processo de filtração. Duas unidades não promoveram alterações nos niveis, permanecendo em 1,5 ppm. A eficiência na remoção do cloro pelo carvão depende do volume de água já filtrada pelo sistema e da sua satuação (Geldreich, 1985). Relacionando as tabelas 1 e 3 , temos que todos os pontos com crescimento na fase de pós filtração (PRÉ e PÓS Retrolavagem) teveram teores de cloro abaixo de $0,5 \mathrm{ppm}$, concentração mínima para evitar crescimento bacteriano e permitindo, por conseqüencia, a forrmação de biofilme.

A World Health Organization (1984), define que $0,5 \mathrm{ppm}$ de cloro ativo no tratamento da água deva ser suficiente para assegurar sua qualidade microbiológica, e, quando associado à filtração em sistemas contendo derivados de prata e carvão ativado, garanta a não formação de biofilme na estrutura do filtro. Porém, de acordo com Daschner (1996), os sistemas fechados de filtro com carvão ativado e prata coloidal permitem a formação de biofilmes. A base interna do reservatório de água destes filtros pode ser considerada a parte mais contaminada do equipamento, superando inclusive os próprios filtros, provavelmente devido a sedimentação de bactérias que podem crescer livremente nesta água desprovida de cloro. O que pode justificar os resultados de crescimento da Tabela 1.

Atualmente são conhecidas cepas de Pseudomonas aeruginosa resistentes a prata e de Criptosporidium parvum resistente a altas concentrações de cloro livre (WHO, 1984; CDC, 1994; Daschner, 1996).

Segundo o fabricante, outro recurso para garantir o fornecimento de água sempre pura é a realização da retrolavagem. Na prática, em nossa instituição, não se verifica a sua realização semanal como indicada pelo fabricante. A despeito disso, o crescimento de mesófilas foi semelhante tanto nas amostras PRÉ, quanto PÓS retrolavagem (Tabela 1), parecendo não haver, nas condições do trabalho, relação entre a qualidade microbiológica da água antes ou após este procedimento.

Muitos autores (Gerdreich, 1985; Payment, 1989; Pires, 1991; Dashner, 1996; 1998) e instituições (Health and Welfare Canada, 1981; German State Institute for Consumer Protection and Veterinary Medicine, 1998) descreveram a deterioração da qualidade microbiologica da água quando filtrada. Alguns sugerem que mesmo quando filtrada essa água deva ser fervida (CDC, 1994; Daschner, 1996; 1998; German Ministry of Health, 1998), outros contra indicam seu uso radicalmente, a ponto de propor a proibição da sua comercialização (Health and Welfare Canada, 1981). 
Os fabricantes devem intensificar as pesquisas para desenvolver uma barreira física contra a entrada de bactérias no sistema e agentes biocidas para diminuir o "regrow" bacteriano (Geldreich, 1985). Ainda devendo ser reguladas por mecanismos nacionais ou internacionais que proibam a produção de filtros que resultem em deterioração da qualidade microbiológica da água por eles filtrada (Daschner 1996). Fato que deve ser melhor compreendido por fabricantes, consumidores e pesquisadores. De acordo com Geldreich (1985):

.. a filtração doméstica deveria ser considerada somente como uma medida provisória, não como uma alternativa viável para um sistema comunitário de água insatisfatório. Os fabricantes deveriam ainda reforçar, junto ao consumidor, a necessidade da troca freqüente dos sistemas. Além, disso estes aparelhos não deveriam ser utilizados em nenhum sistema de água (público ou privado) que não siga as normas padrão quanto a ausência de coliformes.

\section{CONCLUSÃO}

Permanece a questão sobre a real necessidade de se utilizar sistemas de filtração objetivando garantir a qualidade microbiológica da água potável. Observamos neste estudo que a água da rede disponivel no hospital manteve sempre niveis ótimos referentes aos teores de cloro e da qualidade microbiológica. Porém, após filtração, $19,23 \%$ dos filtros testados passaram a apresentar alguma contaminação $(p=0,056)$, ainda que dentro de limites tidos como aceitáveis.

CAVASSIN, E. D.; BELEI, R. A.; PACHENSKI, L. R.; OLIVEIRA, C. H.; CARRILHO, C. M. D.; PERUGINI, M. R. E. Microbiological analysis of filtered water by domestic filters in hospital environment. Semina: Ci. Biol. Saúde, Londrina, v. 20/21, n. 2, p. 49-56, jun. 1999/2000.

\begin{abstract}
Drinkable waters have been described as reservoir for diverse microorganisms. Domestic filters for trading may be found regarding technology and prices, and its manufacturers guarantee the pureness of the processed water by their equipment, some times in a mistaken way. In a hospital environment the water quality control is crucial for developing methods to reduce infections incidence. To verify the role of the domestic filters as source of water contamination in hospital environment, a study of water samples obtained by filtration was performed before and after filter's retro-washing, from 26 filters installed in different points of the hospital. For the control group, non filtered water samples were analyzed from hospital's taps, collected next to the analyzed filters. The samples were microbiologically evaluated through quantitative cultures for mesophiles bacteria and fecal and total coliforms. Chlorine levels surveillance was also carried through. No contamination of the network water samples was verified and its chlorine level stead on 1.5 $\mathrm{ppm}$. Considering culture of the filtered samples before and after retro-washing it was not observed development of fecal or total coliforms, however, it was evidenced the presence of mesophiles bacteria in $19.3 \%(p=0,056)$ whose counting varied from 30 to $100 \mathrm{CFU} / \mathrm{ml}$, with the chlorine levels varying from 0.0 to $1.5 \mathrm{ppm}$. This method of water filtration does not assure its expected pureness, since the microbiologic quality of non filtrated water was superior.
\end{abstract}

KEY WORDS: Microbiology; water; coliforms; domestic filters; mesophiles bacteria.

\title{
REFERÊNCIAS BIBLIOGRÁFICAS
}

ASSOCIAÇÃO BRASILEIRA DAS INDÚSTRIAS DA ALIMENTAÇÃO. Compêndio da legislação de alimentos. São Paulo, 1978. p.7-26.

BRASIL. Portaria $n^{\circ} 36$, de 19 de janeiro de 1990. Aprova normas e padrão de potabilidade da água destinada ao consumo humano. Diário Oficial [da República Federativa do Brasil], Brasilia, v.128, n.16, p.1651-1654, 23 de jan. 1990. Seção 1.

BRASIL. Portaria $n^{\circ} 15$, de 23 de agosto de 1988. Diário Oficial da República Federativa do Brasil. Brasilia, 25 de ago. de 1988.

$\mathrm{CENCI}, \mathrm{G}$. et al. Comparison of fluorogenic and conventional membrane filter media for enumerating coliforme bacteria. Microbios., 76 93060, p.47-54, 1993.

DASCHNER, F. D. Microbiological contamination of drinking water in a comercial household water filter system. Eur. Journal Clinical Microbiology and Infect. Dis., v.15, n.3, p. 233-237, 1996.

DASCHNER FD. Is filtred ou mineral water good for us and for our patients? Infection Control and Hosp. Epidemiology, v. 19, n.12, p. 889-890, dez. 1998.

ENVIROMENTALPROTECTION AGENCY (EPA). National primary drinking water regulations; filtration and disinfection; turbidith and heterotrophic bacteria; proposed rule. Fed. Regist. v.52, p.42178-42222, 1987. 
GELDREICH, E. et. al. Necessity of controlling bacterial populations in potable waters: community water supply. J. Am. Water Works Assoc., v. 64, p. 596-602, 1972

GELDREICH E, et.al. Bacterial colonization of point-of-use water treatment devices. J. Am. Water Works, v.77, p.72-80, 1985.

LeCHEVALLIER MW, et.al. Occurrence of Geardia and Cryptosporidium spp in surface water supplies. Applied and environmental microbilogy, v.57, n.9, p. 2610-2616, set. 1991.

MENDES, C.F. Água. In: MANUAl de Microbiologia Clínica Aplicada ao Controle de Infecçāo Hospitalar. [São Paulo]: Associacão Paulista de Estudos e Controle de Infecção Hospitalar, 1998. p.76-78.

CENTER FOR DISEASE CONTROL AND PRENVENTION. Assessment of inadequality filtred public drinking water. MMR - MORB. MORTAL WEEKLY REP, v. 43, n. 36, p. 661-669, set.1994

PAYMENT, P. Bacterial colonization of domestic reverse osmosis water filtration units. Canadian Journal Microbiology, v. 35, n. 11, p. 1065-1067, Nov. 1989.

PAYMENT, P. et.al. A randomized trial to evaluate the risk of gastrointestinal disease due to consuption of drinking water meeting current microbilogical standards. American Joumal of Public Health. v. 81, n. 6, p. 703-708, June, 1991.
PIRES, C.M.F.; FREITAS, C.P. Atividade bactericida de purificadores de água domésticos. B. Ceppa. Curitiba, v. 8, n. 2, p.74-82, jul/dez. 1990.

REASONER, K.J.; BLANNON, J.C.; GELDREICH, E. Microbilogy of granular activater carbon home treatment devices. In: CONFERENCE ONPROGRESS IN CHEMICAL DESINFECTION (CD-III), 3, 1986. Proceedings... Binghamton: [s.n.] 1986. p. $223-242$

ROBERTS, R.B.; SOAVE, R. Emerging pathogens associated with infections diarrhea. The Brazilian Journal of Infections Diseases, v.1, n.4, p.153-176, agos.1997.

ROSE, J.B. et.al. Survey of potable water supplies for Cryptosporidium and Giardia. Enviromental Science \& Technology., v. 25, n.8, p.1393-1400, 1991.

RUTALA, W.A.; WEBER, D.J. Water as a reservoir of nosocomial pathogens. Infection Control and Hospital Epidemiology. v.18, n.9, p. 609-616, 1991.

SMITH, H.V; ROSE J.B. Waterborne Criptosporidiosis. Parasitology Today. v6, n. 1, p. $8-12,1990$.

WORLD HEALTH ORGANIZATION (WHO). Guidelines for drinking water quality: recommendations. Geneva, 1984. v. 1.

ISAACSON, M.; SAYED, A. R. Health aspects of the use of recycled water in windhoek, SWA/Namibia, 1974-1983. South African Medical Journal, v.73, n.10, may 1988 